\title{
Impact of Yogic Practises on Risk Taking Behavior of Attension Deficit Hyperactivity Disorder Children
}

\author{
Piyush Dubey $^{1 *}$, Garima Singh Kathait ${ }^{1}$, Dr. Anita Puri Singh ${ }^{2}$
}

\section{ABSTRACT}

Attention deficit hyperactivity disorder is one of the most common childhood disorders and can continue through adolescence and adulthood. The purpose of this research was to explore the advantages of yogic practices on risk taking behavior of ADHD. Present study has pre and post experimental design which was conducted on 30 pre diagnosed ADHD School going children with the age group of 8 to 12years selected on random basis. The sample was divided into two control and experimental groups. The Balloon analog risk task (BART) was used for assessment of risk taking behavior of ADHD. The experimental group was given 10 specific yogic practice sessions whereas the control group was given no intervention. Pre and post results indicated that there was no change in the control group in reference to risk taking behavior whereas there was improved in the risk taking behavior of children with ADHD in the experimental group. The positive correlation was found between Yogic practices and risk taking behavior improvement.

Keywords: Attention Deficit Hyperactivity Disorder, Risk Taking Behavior, Inattention, Hyperactivity.

Attention deficit hyperactivity disorder (ADHD) is one of the most common childhood disorders and can continue through adolescence and adulthood. ADHD is a neurobehavioral developmental disorder among school-age children, affecting about 8-12\% of children worldwide. (Faraone SV et al 2003) An epidemiological study by Srinath et al (2005), showed the prevalence of ADHD to be $1.6 \%$ among children less than 16 years, posing costly demands on medical, psychological and societal resources in India. The child with ADHD will have difficulty in concentrating on a task, at home and school. This, predictably, leads to considerable distress among the care givers. (Musa RS et al 2007)

There is a lot of intervention techniques are available for ADHD like medication, yoga, homeopathy, cognitive behavior therapy (CBT), massage therapy, nutrition therapy, naturopathy and hypnosis. The Yoga and Medication are taken for discussion \& review purpose. Yoga is an

\footnotetext{
${ }^{1}$ Ph.D. Scholar, Department of Psychology, Govt. M.L.B. Girls P.G. Autonomous College, Bhopal, (M.P.)

${ }^{2}$ Ph.D. Guide, Department of Psychology, Govt. M.L.B. Girls P.G. Autonomous College, Bhopal, (M.P.)

*Responding Author

(c) 2016 I P Dubey, G Kathait, A Singh; licensee IJIP. This is an Open Access Research distributed under the terms of the Creative Commons Attribution License (http://creativecommons.org/licenses/by/2.0), which permits unrestricted use, distribution, and reproduction in any Medium, provided the original work is properly cited.
} 
ancient technique of India that makes healthy body \& mind both, and Medication is the most common technique all around the world for any physical and mental problem.

\section{Yoga and ADHD}

There are relatively two studies on meditation techniques applied to childhood AD/HD and the one study indicating improvement in impulsivity and improved performance on an attentional measure (Kratter J.1983) and another indicating improved classroom behavior. (Moretti-Altuna G.1987)

Jensen PS \& Kenny DT (2004) yoga considered as a complementary treatment to medication in reducing the behavioral and attention deficit symptoms.

Harrison,et al (2004) studied effect of Sahaja Yoga Meditation (SYM) on improving stability of attention and concentration, motor activity, problems of inhibition, easily frustrated mood, poor self-esteem and difficulties at school of children with ADHD.

Peck, H. et al (2005) examine the effectiveness of yoga on improving attention in elementary school children with attention problems.

This study of mindfulness meditation in adults conducted by Monastra V. (2008) has suggested that it may have beneficial effects on cognitive activities such as shifting set and possibly, in improving working memory

A review by Krisanaprakornkit T. et al (2010) to assess the effectiveness of meditation therapies as a treatment for ADHD. Two studies used mantra meditation while the other two used yoga compared with drugs, relaxation training, non-specific exercises and standard treatment control. Design limitations caused high risk of bias across the studies.

A study conducted by V.R. Hariprasad et al (2013). Children with ADHD and co-operative for yoga were included. There was a significant improvement seen in the ADHD symptoms at the time of discharge.

Meera Balasubramaniam et al (2013) examined the evidence for efficacy of yoga in the treatment of selected major psychiatric disorders. Evidence supported a potential acute benefit for yoga exists in ADHD.

\section{Purpose of the research}

There are many researches on therapeutic interventions for ADHD but there are no as such researches on single alternative therapy like Yoga, meditation or combined models, thus this research work propose to study the comparison of single \& combined model of intervention for treatment of ADHD. Thus the aims and objectives are as follows:- 


\section{Aims \& Objectives}

- To study the effect of individual intervention (yoga and meditation) on risk taking behavior of ADHD suffering children.

\section{Hypothesis}

1) There will be no significant difference between pre and post risk taking behavior score in control group.

2) There will be significant difference between pre and post risk taking behavior score in experimental (yoga intervention) group.

\section{METHODOLOGY}

\section{Study Design}

The study has Pre-and-Post research design. Nature wise it is a pilot study. Two groups formulated respectively - 1 control group and 1 experimental group. Intervention time of therapy is 10 days.

\section{Intervention}

Specific yoga training conducted in 10 sessions of 45 minutes and each session contents $30 \mathrm{~min}$ asana and 15 min trataka practice. Asana sequence as followed:
1) Spot jumping and clapping
2) Vajrasana
3) Supta vajrasana
4) Shashankasana
5) Pashchimottanasan
6) Chakrasana
7) Tadasana
8) trataka

\section{Sample}

- Class: Pre diagnosed ADHD primary school children

- Age group: 8-to-12 year's students

- Gender: Male and female

- Socio economic status: Middle class

- Demography: Urban 


\section{Sample size}

1) Total sample size -30

2) Group 1- 15

3) Group 2- 15

\section{Groups:-}

1) Group 1- Control group

2) Group 2- Experimental group

Tool:- Balloon analogue risk task (BART) online version

\section{Method and Procedure}

1) 20 pre diagnosed school going ADHD children selected.

2) The sample was divided randomly in to two groups of $N / 2$ children.

3) Group $1^{\text {st }}$ is control group.

4) Group $2^{\text {nd }}$ is experimental group (Intervention with Yoga).

5) Pre -risk taking behavior scoring of every group was taken with the help of BART at the beginning of procedure.

6) Excluding $1^{\text {st }}$ control group, other experimental groups was passed with yoga interventions for 10 sessions.

7) After 10 sessions Post- risk taking behavior scoring of every group was taken to assess the reduction in impulsivity symptoms.

\section{STATISTICAL ANALYSIS}

\section{T-Test}

\begin{tabular}{|l|l|l|l|l|l|}
\hline \multicolumn{9}{|c|}{ Paired Samples Statistics } \\
\hline \multirow{2}{*}{} & \multicolumn{2}{c|}{ Mean } & N & Std. Deviation & $\begin{array}{l}\text { Std. } \\
\text { Mean }\end{array}$ \\
\hline \multirow{2}{*}{\begin{tabular}{l} 
Control group \\
\cline { 2 - 6 }
\end{tabular}} & pre & 187.67 & 15 & 15.337 & 3.960 \\
\cline { 2 - 7 } & post & 191.00 & 15 & 13.120 & 3.388 \\
\hline \multirow{2}{*}{$\begin{array}{l}\text { Experimental } \\
\text { group }\end{array}$} & pre & 188.67 & 15 & 14.936 & 3.857 \\
\cline { 2 - 7 } & post & 336.20 & 15 & 15.086 & 3.895 \\
\hline
\end{tabular}




\begin{tabular}{|l|l|l|l|l|}
\hline \multicolumn{5}{|c|}{ Paired Samples Correlations } \\
\hline & & N & Correlation & Sig. \\
\hline Pair 1 & Cont.post \& Cont. pre & 15 & .616 & .015 \\
\hline Pair 2 & Exp. post \& Exp. pre & 15 & -.086 & .761 \\
\hline
\end{tabular}

\begin{tabular}{|c|c|c|c|c|c|c|c|c|c|}
\hline \multicolumn{10}{|c|}{ Paired Samples Test } \\
\hline & & \multicolumn{5}{|c|}{ Paired Differences } & \multirow{3}{*}{ 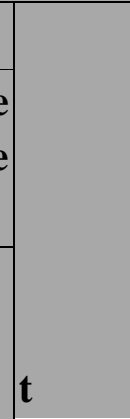 } & \multirow[b]{3}{*}{ df } & \multirow[b]{3}{*}{$\begin{array}{l}\text { Sig. (2- } \\
\text { tailed) }\end{array}$} \\
\hline & & \multirow[b]{2}{*}{ Mean } & \multirow[b]{2}{*}{$\begin{array}{l}\text { Std. } \\
\text { Deviation }\end{array}$} & \multirow[b]{2}{*}{$\begin{array}{l}\text { Std. } \\
\text { Error } \\
\text { Mean }\end{array}$} & \multicolumn{2}{|c|}{$\begin{array}{l}95 \% \text { Confidence } \\
\text { Interval of the } \\
\text { Difference }\end{array}$} & & & \\
\hline & & & & & Lower & Upper & & & \\
\hline Pair1 & $\begin{array}{l}\text { Cont. post } \\
\text { Cont pre }\end{array}$ & -3.333 & 12.630 & 3.261 & -3.661 & 10.328 & 1.022 & 14 & .324 \\
\hline Pair2 & $\begin{array}{l}\text { Exp. post } \\
\text { Exp. pre }\end{array}$ & -147.533 & 22.123 & 5.712 & 135.282 & 159.784 & 25.829 & 14 & .000 \\
\hline
\end{tabular}

\section{DISCUSSION}

There is no significant difference found between pre and post risk taking behavior score in control group thus the first hypothesis proved. And There is significant difference found on the level of $.05 \%$ between pre and post risk taking behavior score in experimental (yoga intervention) group, when degree of freedom is 14 . Then second hypothesis also proved. Results shows yoga intervention reduces risk taking behavior. Pre and post results indicated that there was no change in the control group in reference to risk taking behavior whereas there was improved in the risk taking behavior of children with ADHD in the experimental group. The positive correlation was found between Yogic practices and risk taking behavior improvement.

\section{CONCLUSION}

Pre and post results indicated that there was no change in the control group in reference to risk taking behavior whereas there was improved in the impulsivity of children with ADHD in the experimental group. The positive correlation was found between Yogic practices and risk taking behavior improvement. 


\section{Ethical consideration}

- Written informed consent was obtained from the parents of all students.

- Confidentiality of the obtained data was strictly maintained.

- Participants were informed about absence of any tangible benefits for participating in the study.

There were certain limitations in the study:

1. The sample size was restricted to few children. Hence in future, a similar study needs to be conducted on a larger section of the ADHD children.

2. For avoiding gender differences, both male and female included in the sample.

3. Time limitation is also their.

\section{BIBLIOGRAPHY}

American Psychiatric Association. Text Revision. 4th ed. Washington, DC: American Psychiatric Association; 2000. Diagnostic and Statistical Manual of Mental Disorders.

DSM-5. The Diagnostic and Statistical Manual of Mental Disorders, Fifthth Edition. Washington, DC: American Psychiatric Association.

DSM-IV-TR workgroup. The Diagnostic and Statistical Manual of Mental Disorders, Fourth Edition, Text Revision. Washington, DC: American Psychiatric Association.

Harrison, L., Manocha R., \& Rubia, K. (2004). Sahaja Yoga Meditation as a family treatment programme for children with Attention deficit-hyperactivity disorder. Clinical Child Psychology and Psychiatry, 9(4), 479-497.

Hather L. Peck, Thomas J.Kehle \& Lea A. Theodre,2005, RESEARCH TO PRACTICE:Yoga as an Intervention for Children With AttentionProblems, School Psychology Review,2005, Volume 34, No. 3, pp. 41 5-424

Jensen PS, Kenny DT. 2004. The effects of yoga on the attention and behavior of boys with attention-deficit/hyperactivity disorder (ADHD). J Atten Disord. 2004;7:205-16.

Kratter J. 1983. The use of meditation in the treatment of attention deficit disorder with hyperactivity. Dissertation Abstracts International. 1983;44:p. 1965.

Krisanaprakornkit T, Ngamjarus C, Witoonchart C, Piyavhatkul N., 2010 Jun 16, Meditation therapies for attention-deficit/hyperactivity disorder (ADHD), Cochrane Database Syst Rev. 2010 Jun 16;(6):CD006507. doi: 10.1002/14651858.CD006507.pub2.

Mandanmohan, Jatiya L, Udupa K, Bhavanani AB. 2003 Effect of yoga training on handgrip, respiratory pressures and pulmonary function. Indian J Physiol Pharmacol. 2003;47:38792. 
Manjunath NK, Telles S. 2001. Improved performance in the Tower of London test following yoga. Indian J Physiol Pharmacol. 2001;45:351-4.

Meera Balasubramaniam,' Shirley Telles, and P. Murali Doraiswamy, Yoga on Our Minds: A Systematic Review of Yoga for Neuropsychiatric Disorders, Front Psychiatry. 2012; 3: 117,Published online 2013 January 25. Prepublished online 2012 October 12.

Moretti-Altuna G. 1987. The effects of meditation versus medication in the treatment of attention deficit disorder with hyperactivity. Dissertation Abstracts International. ; 47:p. 4658.

Nayar HS, Mathur RM, Kumar RS. 1975. Effects of yogic exercises on human physical efficiency. Indian J Med Res. 1975;63:1369-76.

Peck, H., Kehle, T., Bray, B., \& Theodore, L. (2005). Yoga as an intervention for children with attention problems. School Psychology Review, 34 (3), 415-424.

Rani JR, Rao KPV. 1996. Meditation and attention regulation. J Indian Psychol. 1996;14:26-30.

Sadiq AJ. 2007. Attention-deficit/hyperactivity disorder and integrative approaches. Pediatr Ann.2007;36:508-15.

Sahay BK, Sadasivudu B, Yogi R, Bhaskaracharyulu C, Raju PS, Madhavi S, et al. 1982. Biochemical parameters in normal volunteers before and after yogic practices. Indian $J$ Med Res.1982;76(Suppl):144-8.

Selvamurthy WN, Nayar HS, Joseph NT, Joseph S. 1983. Physiological effects of yogic practices.NIMHANS J. 1983;1:71-80.

Sharma VK, Das S, Mondal S, Goswami U, Gandhi A. 2006. Effect of Sahaj Yoga on neurocognitive functions in patients suffering from major depression. Indian $J$ Physiol Pharmacol. 2006;50:375-83.

Sridevi K, Sitamma M. 1998. Yoga training and cognitive task performance. $J$ Indian Psychol.1998;16:34-9.

Srinath S, Girimaji SC, Gururaj G, Seshadri S, Subbakrishna DK, Bhola P, et al. 2005. Epidemiological study of child and adolescent psychiatric disorders in urban and rural areas of Bangalore, India. Indian J Med Res. 2005;122:67-79.

Udupa K, Madanmohan, Bhavanani AB, Vijayalakshmi P, Krishnamurthy N. 2003. Effect of pranayam training on cardiac function in normal young volunteers. Indian $J$ Physiol Pharmacol. ;47:27-33.

V. R. Hariprasad, R. Arasappa, S. Varambally, S. Srinath, and B. N. Gangadhar,2013, Feasibility and efficacy of yoga as an add-on intervention in attention deficit-hyperactivity disorder: An exploratory study,Indian J Psychiatry. 2013 July; 55(Suppl 3): S379-S384.

Verma IC, Jayashanka rappa BS, Palani M. 1982. Effect of transcendental meditation on the performance of some cognitive psychological tests. Indian J Med Res. ;76(Suppl):13643.

Yadav RK, Das S. 2001. Effect of yogic practice on pulmonary functions in young females. Indian J Physiol Pharmacol. ;45:493-6. 